\title{
BMJ Open Familial transmission of chronic obstructive pulmonary disease in adoptees: a Swedish nationwide family study
}

\author{
Bengt Zöller, ${ }^{1}$ Xinjun Li, ${ }^{1}$ Jan Sundquist, ${ }^{1,2}$ Kristina Sundquist ${ }^{1,2}$
}

To cite: Zöller B, Li X, Sundquist $\mathrm{J}$, et al. Familial transmission of chronic obstructive pulmonary disease in adoptees: a Swedish nationwide family study. BMJ Open 2015;5:e007310.

doi:10.1136/bmjopen-2014007310

- Prepublication history and additional material is available. To view please visit the journal (http://dx.doi.org/ 10.1136/bmjopen-2014007310).

Received 27 November 2014 Accepted 30 December 2014

CrossMark

\footnotetext{
${ }^{1}$ Center for Primary Health Care Research, Lund University, Malmö, Sweden ${ }^{2}$ Stanford Prevention Research Centre, Stanford University School of Medicine, Stanford, California, USA
}

Correspondence to Dr Bengt Zöller; bengt.zoller@med.Iu.se

\section{ABSTRACT}

Objectives: Familial clustering of chronic obstructive pulmonary disease (COPD) is well established, but the familial risk of COPD has not been determined among adoptees. The aim was to determine whether the familial transmission of COPD is related to disease in biological and/or adoptive parents.

Design: Historic cohort study.

Participants: 80214 (50\% females).

Methods: The Swedish Multi-Generation Register was used to follow all Swedish-born adoptees born in 1932-2004 ( $n=80214)$ between 1 January 1964 and 31 December 2010 for COPD $(n=1978)$. The risk of COPD was estimated in adoptees with at least one biological parent with COPD but no adoptive parent with COPD $(n=162)$ compared with adoptees without a biological or adoptive parent with COPD. The risk of COPD was also determined in adoptees with at least one adoptive parent but no biological parent with COPD $(n=110)$, and in adoptees with both affected biological and adoptive parents $(n=162)$.

Primary outcome measure: COPD in adoptees. Results: Adoptees with COPD in at least one biological parent but no adoptive parent were more likely to have COPD than adoptees without a biological or adoptive parent with COPD (standardised incidence ratio, SIR=1.98 (95\% Cl 1.69 to 2.31)). The familial SIR for adoptees with both a biological parent and an adoptive parent with COPD was 1.68 (95\% Cl 1.39 to 2.00$)$. Adoptees with at least one adoptive parent with COPD but no biological parent with COPD were not at an increased risk of COPD (SIR=1.12 (95\% Cl 0.92 to 1.35)).

Conclusions: The findings of the study show that the familial transmission of COPD is associated with COPD in biological but not adoptive parents, suggesting that genetic or early life factors are important in the familial transmission of COPD.

\section{INTRODUCTION}

The major cause of chronic obstructive pulmonary disease (COPD) is tobacco smoking, but the pathobiology of COPD involves a

\section{Strengths and limitations of this study}

- To the best of our knowledge, this is the first nationwide study of adoptees to determine whether the familial transmission of chronic obstructive pulmonary disease (COPD) is related to disease in biological and/or adoptive parents.

- The present study designs allowed us to determine whether the familial transmission of COPD among adoptees is related to COPD in biological and/or adoptive parents.

- A limitation is the lack of smoking data, though the familial risks were adjusted for socioeconomic factors, which are related to lifestyle factors such as smoking.

- This is a register-based study which does not allow us to determine how COPD was diagnosed.

- Unknown confounders may lead to overestimation or underestimation of the familial risks.

complex interaction between several factors, including genetic susceptibility. ${ }^{1}$ Family history of COPD is a well-established risk factor for COPD. ${ }^{1-4}$ In Sweden, COPD shows a high familial risk (standardised incidence ratio, SIR) among siblings of 4.65, compared with those without family history. ${ }^{3}$ It has been shown that genetic variants resulting in $\alpha 1$-antitrypsin (AAT) deficiency lead to COPD. ${ }^{5}$ However, AAT deficiency accounts for only $1-2 \%$ of all COPD cases. ${ }^{6}$ Thus, other variants in the genome are likely to be associated with COPD traits. Although an increasing number of COPD susceptibility genes have been identified, ${ }^{16-8}$ much about the genetics of COPD remains to be discovered. ${ }^{6} \mathrm{~A}$ twin study estimated the heritability of COPD to be $55 \%(36-71 \%)$ in women, whereas $25 \%$ (8$41 \%$ ) of the susceptibility to COPD in men was due to family environment, rather than genetic factors. ${ }^{9}$ Among Swedish twins, the heritability estimate for COPD was a moderate $40 \%$ and only $14 \%$ of the genetic influences were shared with smoking, suggesting that 
genetic factors independent of those related to smoking habits play a role in the development of COPD. ${ }^{10}$ Among Danish and Swedish twins, the susceptibility to severe COPD, as defined by hospitalisation, was strongly influenced by genetic factors, with $60 \%$ heritability. ${ }^{11}$ It is difficult to disentangle the contributions of genetic and family environmental factors in family studies of COPD because most children, including dizygotic (DZ) and monozygotic (MZ) twins, grow up in their biological families. ${ }^{12-14}$ The most critical assumption in twin studies is that MZ and DZ twins show similarities because of the sharing of environmental factors, so that the difference in concordance rates between MZ and DZ twins is only a reflection of genetic factors. ${ }^{14}$ Another possible avenue for studying whether genetic and family environmental factors have differential influences on the transmission of COPD is a follow-up study of a large sample of adoptees. ${ }^{14}$ Studies of adoptees offer a unique opportunity to study the genetic transmission of COPD because adoptees do not grow up in their biological families. ${ }^{14}$ Transmission of COPD from biological parents to offspring would therefore be explained by genetic factors or early life factors rather than family environment. In addition, transmission of COPD from adoptive parents to their non-biological offspring would be explained by family environment rather than genetic factors.

The Swedish Multi-Generation Register consists of data on more than nine million individuals born from 1932 onwards and links all adoptees born in Sweden since 1932 to their biological and adoptive parents. ${ }^{15} 16$ In previous studies of coronary heart disease, venous thromboembolism, breast cancer, prostate cancer and colorectal cancer in adoptees, it was possible to link Swedish-born adoptees to their biological and adoptive parents. ${ }^{17-19}$

\section{Aims}

To the best of our knowledge, no previous study of familial transmission of COPD has focused on adoptees. This study used the Swedish Inpatient Register ${ }^{20}{ }^{21}$ the Swedish Outpatient Care Register, ${ }^{21}$ The Swedish Cause of Death Register $^{21}$ and the Swedish Multi-Generation Register $^{15} 1621$ and had two primary aims: (1) to examine the risk of COPD in adoptees with at least one biological parent but no adoptive parent affected by COPD and (2) to examine the risk of COPD in adoptees with at least one adoptive parent but no biological parent affected by COPD. Additionally, we examined the familial risk of COPD in offspring with COPD in biological and adoptive parents. The control groups consisted of adoptees without a biological or adoptive parent affected by COPD.

\section{METHODS}

\section{Data sources}

The data set used in this historic (or retrospective) cohort study was constructed by linking the Total Population Register, the Multi-Generation Register, the Swedish
Inpatient Register, the Swedish Outpatient Care Register and the Swedish Cause of Death Register, which were provided by Statistics Sweden and the National Board of Health and Welfare. ${ }^{15} 162021$ Information from the various registers in the database is linked at the individual level via the national 10-digit personal identification number assigned to each resident in Sweden during his or her lifetime ${ }^{22}$ Prior to inclusion in the data set, civic registration numbers were replaced by serial numbers to preserve the anonymity of all individuals. Using these linked data, we were able to identify our study population80214 Swedish-born adoptees born between 1932 and 2004-and link them to their biological and adoptive parents. ${ }^{17-19}$ The analyses were limited to Swedish-born adoptees because first-generation immigrants cannot be linked to their biological parents if the latter are not registered in Sweden. Data for age at adoption were not available. However, other studies have shown that: (1) most adoptions resulted from unwanted pregnancies in young unmarried women; (2) the children were taken into institutional care by the municipalities shortly after birth; (3) the median age at adoption was 6 months; (4) most children were adopted before the age of 12 months; (5) boys were usually adopted at a later age than girls and (6) children with early signs of disability were often exempted from adoption and cared for in foster care or institutions. ${ }^{23-25}$

\section{Definition of biological/adoptive parent history of COPD and outcome variables}

The history of COPD in biological or adoptive parents was determined by first diagnosis of COPD in the Swedish Inpatient Register any time during the study period (1964-2010), the Swedish Outpatient Care register (2001-2010) and the Swedish Cause of Death Register (1964-2010) for biological or adoptive parents, respectively. Thus, offspring might be diagnosed before biological and/or adoptive parents in order not to misclassify parents who are later diagnosed with COPD. Only main and second diagnoses were considered to ensure high validity. The outcome variable was first diagnosis of COPD during the same time period for adoptees. The 7th, 8th, 9th and 10th revisions of the International Classification of Diseases (ICD) were used to identify these cases (see online supplementary table S1). The validity and coverage of the Swedish Inpatient Register is high. ${ }^{20}$ COPD diagnoses from the Swedish Inpatient Register are misclassified or uncertain in less than $10 \%$ of cases. $^{26}$

\section{Explanatory variables}

Sex was categorised as male or female. Age at first COPD diagnosis was categorised into 5-year groups. Education level was classified into three categories: completion of compulsory schooling or less (9 years), completion of high school or some theoretical high school (10-12 years) and education after high school (>12 years). Time period was divided into 5-year intervals. Geographic region of 
residence was divided into large cities (those with a population of $>200000$, ie, Stockholm, Gothenburg and Malmö), Southern Sweden and Northern Sweden.

\section{Statistical analysis}

Person-years were calculated for adoptees from the start of the study period (1 January 1964) until first diagnosis of COPD, death, emigration or the end of the study period (31 December 2010). Age-specific SIRs for first diagnosis of COPD during the study period were calculated for the entire study period, and are presented with 95\% CIs. ${ }^{27}$ Familial risks for adoptees with at least one biological and/or adoptive parent with COPD were calculated by comparison with adoptees whose biological and adoptive parents were not affected by COPD. The familial risks for COPD in adoptees with at least one biological parent with COPD compared with those without a biological parent with COPD was also determined. In a similar way, we also determined the familial risks for COPD in adoptees with at least one adoptive parent with COPD compared with those without an adoptive parent with COPD. This stratification was made in an effort to separate the contribution from COPD in biological and adoptive parents, and the combination of COPD in biological and adoptive parents.

The SIRs for adoptees were calculated as the ratio of observed (O) and expected (E) numbers of COPD cases using the indirect standardisation method:

$$
\mathrm{SIR}=\frac{\sum_{\mathrm{j}=1}^{J} \mathrm{o}_{\mathrm{j}}}{\sum_{\mathrm{j}=1}^{J} \mathrm{n}_{\mathrm{j}} \lambda_{\mathrm{j}}^{*}}=\frac{\mathrm{O}}{\mathrm{E}^{*}},
$$

where $\mathrm{O}=\sum \mathrm{o}_{\mathrm{j}}$ denotes the total observed number of cases in the study group; $\mathrm{E}^{*}$ (expected number) is calculated by applying stratum-specific standard incidence rates $\left(\lambda_{j}^{*}\right)$ obtained from the reference group to the stratum-specific person-years $\left(n_{j}\right)$ of risk for the study group; $o_{j}$ represents the observed cases that the cohort subjects contribute to the jth stratum; and J represents the strata defined by cross-classification of the different adjustment variables (sex (not sex-specific risks), age group, education level, time period and geographic region of residence). ${ }^{27}$ The $95 \%$ CIs were calculated assuming a Poisson distribution. ${ }^{27}$

\section{RESULTS}

Of the 80214 adoptees born during 1932-2004, 1978 were diagnosed with COPD during the study period (1964-2010; table 1). The overall rate of COPD in adoptees was 85.6/100 000 person-years. The COPD rate was $141.7 / 100000$ person-years in adoptees with at least one biological parent with COPD, compared with 117.6/ 100000 person-years in adoptees with an adoptive parent with COPD. The distributions of sex, age at COPD diagnosis, birth year, education level, geographic region of residence and time period for COPD diagnosis are shown in table 1 . The mean age of the 1978 adoptees at COPD diagnosis was $55.93 \pm 13.46$ years $($ mean $\pm \mathrm{SD}$; not shown in table 1). The mean age at COPD diagnosis for the 283 adoptees with affected biological parents was 53.21 \pm 11.05 years, significantly lower $(p<0.001)$ than the mean age at COPD diagnosis for the 1695 adoptees without affected biological parents $(56.38 \pm 13.78$ years $)$. The mean age at COPD diagnosis for the 231 adoptees with affected adoptive parents was $55.70 \pm 12.18$ years, which was significantly but only slightly lower $(p=0.030)$ than the mean age at diagnosis for the 1747 adoptees without affected adoptive parents $(55.95 \pm 13.63$ years $)$.

\section{Familial risks in adoptees with affected biological and adoptive parents}

In total, 50 men and 71 women had an affected biological parent and an affected adoptive parent (table 2). The familial SIR for adoptees with a biological parent and an adoptive parent with COPD was 1.68 (95\% CI 1.39 to 2.00). The familial risk was increased in men $(\mathrm{SIR}=1.63)$ and women ( $\mathrm{SIR}=1.71$; table 2). Adoptees with at least one biological parent with COPD but no adoptive parent with COPD were more likely to have COPD than adoptees without a biological or an adoptive parent with COPD (SIR=1.98 (95\% CI 1.69 to 2.31)). The familial risk was increased in men $(\mathrm{SIR}=1.67)$ and women $(\mathrm{SIR}=2.24$; table 2$)$. There was a tendency for higher SIR among women, but the $95 \%$ CIs are overlapping. Familial risk of COPD tended to be lower in older individuals ( $\geq 60$ years) for adoptees with only affected biological parents (table 2). Adoptees with at least one adoptive parent with COPD but no biological parent with COPD were not at an increased risk of COPD (SIR=1.12 (95\% CI 0.92 to 1.35$)$ ). Stratified analysis showed no increased risk of COPD for men or women or for any age group in adoptees with only affected adoptive parents.

\section{Additional analysis}

The SIRs for COPD in adoptees with at least one biological parent with COPD compared with those without a biological parent with COPD are shown in table 3 according to age. The overall SIR for adoptees with at least one biological parent with COPD was 1.84 (95\% CI 1.63 to 2.07), after adjustment for sex, age at first COPD diagnosis, education level, time period and geographic region of residence. Increased familial risk was observed in all age groups (table 3 ).

The SIRs for COPD in adoptees with at least one adoptive parent with COPD compared with those without an adoptive parent with COPD are shown in table 4. The overall SIR for adoptees with at least one adoptive parent with COPD was slightly increased (SIR=1.28 (95\% CI 1.12 to 1.45)), after adjustment for age at first COPD diagnosis, education level, time period and geographic region of residence (table 4). This increased risk was driven by the inclusion of 121 cases who also had one biological parent with COPD (tables 2 and 3).

No significant increased risk of COPD was observed for adoptees younger than 50 years of age. The SIR was 
Table 1 Demographics, population size, number of cases of chronic obstructive pulmonary disease (COPD) and age-adjusted rate of COPD (per 100000 person-years) between 1 January 1964 and 31 December 2010 in Swedish-born adoptees born during 1932-2004

\begin{tabular}{|c|c|c|c|c|c|c|}
\hline & \multicolumn{2}{|c|}{ Population } & \multicolumn{4}{|c|}{ COPD events } \\
\hline & $\mathbf{N}$ & Per cent & $\mathbf{N}$ & Per cent & $\begin{array}{l}\text { Incidence rate } \\
\text { (per } 100000 \\
\text { person-years) }\end{array}$ & $95 \% \mathrm{Cl}$ \\
\hline $\begin{array}{l}\text { Total population and overall COPD incidence rate } \\
\text { Gender }\end{array}$ & 80214 & & 1978 & & 85.6 & 81.8 to 89.4 \\
\hline Male & 39933 & 49.8 & 851 & 43.0 & 78.6 & 73.3 to 83.9 \\
\hline Female & 40281 & 50.2 & 1127 & 57.0 & 92.0 & 86.7 to 97.4 \\
\hline \multicolumn{7}{|l|}{ Age at diagnosis (years) } \\
\hline$<40$ & & & 196 & 9.9 & 8.8 & 7.6 to 10.1 \\
\hline $40-49$ & & & 241 & 12.2 & 38.5 & 33.7 to 43.4 \\
\hline $50-59$ & & & 623 & 31.5 & 147.3 & 135.8 to 158.9 \\
\hline$\geq 60$ & & & 918 & 46.4 & 413.9 & 387.1 to 440.6 \\
\hline \multicolumn{7}{|l|}{ Birth year } \\
\hline 1932-1939 & 7891 & 9.8 & 521 & 26.3 & 65.3 & 59.7 to 71.0 \\
\hline 1940-1949 & 23414 & 29.2 & 901 & 45.6 & 91.2 & 85.3 to 97.2 \\
\hline $1950-1959$ & 21012 & 26.2 & 373 & 18.9 & 46.2 & 41.5 to 50.9 \\
\hline 1960-1969 & 18648 & 23.2 & 121 & 6.1 & 44.3 & 36.4 to 52.2 \\
\hline 1970-1979 & 6817 & 8.5 & 47 & 2.4 & 25.3 & 18.0 to 32.5 \\
\hline 1980-2004 & 2432 & 3.0 & 15 & 0.8 & 11.2 & 5.5 to 16.8 \\
\hline \multicolumn{7}{|l|}{ Period of diagnosis } \\
\hline $1964-1973$ & & & 29 & 1.5 & 8.7 & 5.5 to 11.9 \\
\hline 1974-1983 & & & 81 & 4.1 & 13.2 & 10.3 to 16.0 \\
\hline 1984-1993 & & & 148 & 7.5 & 30.8 & 25.8 to 35.8 \\
\hline 1994-1903 & & & 620 & 31.3 & 68.5 & 63.1 to 73.9 \\
\hline 2004 or later & & & 1075 & 54.3 & 89.0 & 83.6 to 94.3 \\
\hline \multicolumn{7}{|l|}{ Education level (years) } \\
\hline$\leq 9$ & 12675 & 15.8 & 466 & 23.6 & 98.5 & 89.6 to 107.5 \\
\hline $10-11$ & 50786 & 63.3 & 1260 & 63.7 & 94.3 & 89.1 to 99.5 \\
\hline$\geq 12$ & 16753 & 20.9 & 252 & 12.7 & 51.1 & 44.8 to 57.4 \\
\hline \multicolumn{7}{|l|}{ Geographic region of residence } \\
\hline Large cities & 57546 & 71.7 & 1665 & 84.2 & 84.0 & 79.9 to 88.0 \\
\hline Southern Sweden & 16611 & 20.7 & 235 & 11.9 & 118.4 & 103.3 to 133.5 \\
\hline Northern Sweden & 6057 & 7.6 & 78 & 3.9 & 106.9 & 83.2 to 130.7 \\
\hline \multicolumn{7}{|l|}{ Biological parent(s) with COPD } \\
\hline Yes & 8554 & 10.7 & 283 & 14.3 & 141.7 & 125.2 to 158.2 \\
\hline No & 71660 & 89.3 & 1695 & 85.7 & 81.1 & 77.2 to 85.0 \\
\hline \multicolumn{7}{|l|}{ Adoptive parent(s) with COPD } \\
\hline Yes & 7928 & 9.9 & 231 & 11.7 & 117.6 & 102.4 to 132.8 \\
\hline No & 72286 & 90.1 & 1747 & 88.3 & 82.9 & 79.0 to 86.8 \\
\hline
\end{tabular}

only slightly increased in the two oldest age groups (table 4).

\section{Sensitivity analysis}

Patients with AAT deficiency (ICD-10 E88.0 and ICD-9 277G) were excluded (see online supplementary table S1). Only three familial cases with AAT deficiency (ie, with a family history of COPD in biological parents) were found $(3 / 283=1.1 \%)$. The familial risks of COPD in adoptees with an affected biological parent after exclusion of AAT deficiency were similar to results presented in table 3 (see online supplementary table S2).

One case of AAT deficiency was found in adoptees with an affected adoptive parent (1/231=0.43\%). The familial risks of COPD in adoptees with an affected adoptive parent after exclusion of AAT deficiency were similar to results presented in table 4 (see online supplementary table S2).

\section{DISCUSSION}

This follow-up study of 80214 Swedish adoptees linked to both their biological and adoptive parents shows that adoptees with at least one biological parent with COPD were more likely to have COPD than adoptees without a biological parent with COPD (tables 2 and 3). These novel findings implicate genetic or early life factors in the familial transmission of COPD. In contrast, the overall risk of COPD in adoptees with at least one adoptive parent with COPD was only increased in adoptees 
Table 2 SIR of COPD in adoptees with COPD in biological and adoptive parents ( $N=80214)$

\begin{tabular}{|c|c|c|c|c|c|c|c|c|c|c|}
\hline \multirow[b]{2}{*}{ Age at diagnosis (years) } & \multicolumn{3}{|c|}{ Males } & \multicolumn{4}{|c|}{ Females } & \multicolumn{3}{|l|}{ All } \\
\hline & $\mathbf{0}$ & SIR & $95 \% \mathrm{Cl}$ & $\mathbf{0}$ & SIR & $95 \% \mathrm{Cl}$ & & $\overline{\mathbf{O}}$ & SIR & $95 \% \mathrm{Cl}$ \\
\hline $\begin{array}{l}\text { Both biological and adoptive parents } \\
\text { without COPD }\end{array}$ & 693 & & Reference & 892 & & Reference & & 1585 & & Reference \\
\hline \multicolumn{11}{|c|}{ Both biological and adoptive parents with COPD } \\
\hline$<50$ & 14 & 1.49 & 0.81 to 2.51 & 21 & 1.76 & 1.09 & 2.69 & 35 & 1.64 & 1.14 to 2.28 \\
\hline $50-59$ & 27 & 2.25 & 1.48 to 3.28 & 27 & 1.69 & 1.11 & 2.47 & 54 & 1.93 & 1.45 to 2.52 \\
\hline$\geq 60$ & 9 & 0.97 & 0.44 to 1.85 & 23 & 1.69 & 1.07 & 2.53 & 32 & 1.40 & 0.96 to 1.97 \\
\hline All & 50 & 1.63 & 1.21 to 2.15 & 71 & 1.71 & 1.33 & 2.16 & 121 & 1.68 & 1.39 to 2.00 \\
\hline \multicolumn{11}{|l|}{ Only biological parents with COPD } \\
\hline$<50$ & 20 & 1.85 & 1.13 to 2.86 & 29 & 2.29 & 1.53 & 3.29 & 49 & 2.08 & 1.54 to 2.76 \\
\hline $50-59$ & 28 & 2.06 & 1.36 to 2.97 & 41 & 2.33 & 1.67 & 3.16 & 69 & 2.21 & 1.72 to 2.80 \\
\hline$\geq 60$ & 13 & 1.08 & 0.57 to 1.84 & 31 & 2.08 & 1.41 & 2.96 & 44 & 1.63 & 1.19 to 2.19 \\
\hline All & 61 & 1.67 & 1.28 to 2.15 & 101 & 2.24 & 1.82 & 2.72 & 162 & 1.98 & 1.69 to 2.31 \\
\hline \multicolumn{11}{|l|}{ Only adoptive parents with COPD } \\
\hline$<50$ & 8 & 0.87 & 0.37 to 1.73 & 8 & 0.75 & 0.32 & 1.49 & 16 & 0.81 & 0.46 to 1.32 \\
\hline $50-59$ & 15 & 1.07 & 0.60 to 1.77 & 21 & 1.15 & 0.71 & 1.77 & 36 & 1.12 & 0.78 to 1.55 \\
\hline$\geq 60$ & 24 & 1.13 & 0.72 to 1.68 & 34 & 1.37 & 0.95 & 1.92 & 58 & 1.26 & 0.96 to 1.63 \\
\hline All & 47 & 1.06 & 0.78 to 1.41 & 63 & 1.18 & 0.90 & 1.51 & 110 & 1.12 & 0.92 to 1.35 \\
\hline
\end{tabular}

Bold: $95 \% \mathrm{Cl}$ does not include 1.00 .

SIRs are adjusted for sex (not sex-specific SIRs), age, time period, geographic region of residence and educational level. SIRs for males are calculated only for males with and without a family history, and SIRs for females are calculated only for females with and without a family history.

COPD, chronic obstructive pulmonary disease; O, observed number of cases; SIR, standardised incidence ratio.

who also had an affected biological parent (tables 2 and 4). The importance of family history in the development of COPD is well established. ${ }^{1-5}$ Although it is well known that genetic factors contribute to the risk of COPD,${ }^{1-11}$ our finding that genetic or early life factors seem to be more important for the familial transmission of COPD than family environmental factors is novel (tables 2-4). The potential to disentangle the contributions of genetic or early life factors and family environmental factors to the familial transmission of COPD stems from the fact that adoptees do not share the same family environment as their biological parents. ${ }^{14}$ This study provides important knowledge for the planning of future studies to explain the missing familial heritability in COPD. Most of the familial inheritance is not related to AAT deficiency. Moreover, the present data have important clinical implications. A biological family history of COPD suggests a genetic susceptibility to COPD and increased sensitivity to the effect of smoking. However, owing to the lack of smoking data in this study, we cannot exclude that not only genetic factors directly involved in the COPD pathophysiology but also genetic factors related to cigarette smoking are involved. Cigarette smoking has both a familial environmental and a genetic cause. ${ }^{28}$

It is surprising that the risk was not higher in adoptees with both affected biological and adoptive parents (table 2). Instead, it seems that most of the effect was driven by COPD in biological but not adoptive parents (tables 2-4). The cause of this is unclear but one explanation might be the limited number of cases related to disease in biological and/or adoptive parents. Another surprising issue is that adoptees with COPD in their adoptive parents (but not biological parents) were not at an increased COPD risk (table 2), given the fact that smoking in the family is a risk factor for COPD (shared environment, passive smoking, shared values and habits, parental guidance, etc). This suggests that smoking in certain individuals is not a sufficient risk factor without a biological inheritance.

Table 3 SIR of COPD in adoptees with biological parent(s) diagnosed with COPD ( $N=80214)$

\begin{tabular}{|c|c|c|c|c|c|c|c|c|c|}
\hline \multirow[b]{2}{*}{ Age at diagnosis (years) } & \multicolumn{3}{|c|}{ Males } & \multicolumn{3}{|c|}{ Females } & \multicolumn{3}{|l|}{ All } \\
\hline & $\overline{0}$ & SIR & $95 \% \mathrm{Cl}$ & $\overline{0}$ & SIR & $95 \% \mathrm{Cl}$ & 0 & SIR & $95 \% \mathrm{Cl}$ \\
\hline$<50$ & 34 & 1.69 & 1.17 to 2.37 & 50 & 2.07 & 1.54 to 2.73 & 84 & 1.90 & 1.51 to 2.35 \\
\hline $50-59$ & 55 & 2.11 & 1.59 to 2.75 & 68 & 2.04 & 1.59 to 2.59 & 123 & 2.07 & 1.72 to 2.47 \\
\hline$\geq 60$ & 22 & 1.02 & 0.64 to 1.54 & 54 & 1.89 & 1.42 to 2.46 & 76 & 1.51 & 1.19 to 1.89 \\
\hline All & 111 & 1.64 & 1.35 to 1.97 & 172 & 2.00 & 1.71 to 2.32 & 283 & 1.84 & 1.63 to 2.07 \\
\hline
\end{tabular}

Bold: $95 \% \mathrm{Cl}$ does not include 1.00.SIRs are adjusted for sex (not sex-specific SIRs), age, time period, geographic region of residence and educational level. SIRs for males are calculated only for males with and without a family history, and SIRs for females are calculated only for females with and without a family history.

COPD, chronic obstructive pulmonary disease; O, observed number of cases; SIR, standardised incidence ratio. 
Table 4 SIR of COPD in adoptees with adoptive parent(s) diagnosed with COPD ( $N=80214)$

\begin{tabular}{|c|c|c|c|c|c|c|c|c|c|}
\hline \multirow[b]{2}{*}{ Age at diagnosis (years) } & \multicolumn{3}{|c|}{ Males } & \multicolumn{3}{|c|}{ Females } & \multicolumn{3}{|l|}{ All } \\
\hline & $\mathbf{0}$ & SIR & $95 \% \mathrm{Cl}$ & $\mathbf{0}$ & SIR & $95 \% \mathrm{Cl}$ & $\mathbf{0}$ & SIR & $95 \% \mathrm{Cl}$ \\
\hline$<50$ & 22 & 1.11 & 0.69 to 1.68 & 29 & 1.17 & 0.78 to 1.68 & 51 & 1.14 & 0.85 to 1.50 \\
\hline $50-59$ & 42 & 1.4 & 1.06 to 2.00 & 48 & 1.30 & 0.96 to 1.72 & 90 & 1.38 & 1.11 to 1.69 \\
\hline$\geq 60$ & 33 & 1.07 & 0.74 to 1.51 & 57 & 1.42 & 1.08 to 1.84 & 90 & 1.27 & 1.02 to 1.56 \\
\hline All & 97 & 1.23 & 1.00 to 1.50 & 134 & 1.31 & 1.10 to 1.56 & 231 & 1.28 & 1.12 to 1.45 \\
\hline
\end{tabular}

Bold: $95 \% \mathrm{Cl}$ does not include 1.00

SIRs are adjusted for sex (not sex-specific SIRs), age, time period, geographic region of residence and educational level. SIRs for males are calculated only for males with and without a family history, and SIRs for females are calculated only for females with and without a family history.

COPD, chronic obstructive pulmonary disease; O, observed number of cases; SIR, standardised incidence ratio.

\section{Strengths and limitations}

One strength of this study is the use of the validated Swedish Inpatient Register. The Swedish Inpatient Register has high validity and coverage. ${ }^{20} 21$ The validity for COPD diagnoses is around $90 \%$ according to the Gold criteria. ${ }^{26}{ }^{29}$ Moreover, a previous report has shown that among patients with COPD the following ICD-9 codes that we used are common: 496 for COPD (82\%), ICD-9 code 492 for emphysema (23\%) and ICD-9 code 491 for chronic bronchitis (31\%). In total, $82 \%$ of patients with COPD had multiple ICD-9 codes. ${ }^{30}$ Another advantage is that the use of the Swedish Inpatient Register eliminated potential recall bias. Recall and selfreport bias are common problems in many case-control studies and other studies of familial transmission of COPD that rely on self-report. Self-report bias is likely to be especially problematic in adoptee studies because many adoptees have no knowledge of the health status of their biological parents. The unique Swedish Total Population Register is highly complete (almost 100\%). ${ }^{15}$ The use of Swedish personal identification numbers made it possible to track each individual in the different data registers, which eliminated loss to follow-up. ${ }^{22}$

An important limitation of this study is the lack of information on individual risk factors for COPD, notably smoking. However, the median age at adoption was 6 months and most children were adopted before the age of 12 months. ${ }^{23-25}$ Thus, familial exposure for smoking should therefore be expected to be more related to smoking in adoptive parents than among biological parents. Moreover, the familial risks were adjusted for socioeconomic factors, which are related to lifestyle factors such as smoking. Non-paternity is another potential source of bias in studies of familial transmission. Adoptee studies may be affected by non-paternity and non-maternity due to hidden adoptions (ie, when a child is never told that he or she was adopted). Our study, however, was not significantly affected by this potential source of bias because all adoptions in Sweden are registered in a nationwide database. In addition, the large number of comparisons is a point worthy of consideration. While some researchers advocate correcting for multiple comparisons, others suggest that this is not necessary in observational studies. ${ }^{31}$
Some children may have been adopted by biological relatives. If this was common, an increased risk for COPD in adoptees with affected adoptive parents could be expected, which was not the case. Another limitation is that we had no information about the age at which children were adopted, although it is likely that most adoptions occurred in early childhood. In previous studies, the majority of children were adopted before 12 months of age. ${ }^{20-22}$ Other unknown confounders may also lead to overestimation or underestimation of the familial risks. We do not know the coverage of COPD diagnosis in the present registers. However, as most adoptees were adopted early, one should expect that a higher awareness should be expected in adoptees with affected adoptive parents compared to adoptives with affected biological parents. This is therefore not likely to bias our results to any major degree.

This study included only adoptees born in Sweden. We therefore cannot generalise this study to populations of non-European origin. However, the Swedish population is, for instance, genetically closely related to British and German people. ${ }^{21}$ Results from Swedish nationwide family studies such as this study are therefore likely to be valid for many individuals of Caucasian origin in Europe and the USA. ${ }^{21}$

\section{Conclusions}

The novel findings of this study implicate genetic or early life factors in the familial transmission of COPD. Family history of COPD signals a potential genetic susceptibility to COPD.

Acknowledgements The registers used in the study are maintained by Statistics Sweden and the National Board of Health and Welfare.

Contributors All authors contributed to the conception and design of the study and data analysis and interpretation. JS and KS acquired the data. BZ drafted the manuscript, and all authors revised it critically and approved the final version. $B Z$ is the guarantor.

Funding This work was supported by grants awarded to Dr Bengt Zöller by the Swedish Heart-Lung Foundation; ALF funding awarded to Dr Bengt Zöller, Dr Kristina Sundquist and Dr Jan Sundquist by Region Skåne; grants awarded to Dr Kristina Sundquist and Dr Jan Sundquist by the Swedish Research Council (K2009-70X-15428-05-3 and K2012-70X-15428-08-3); and grants awarded to Dr Jan Sundquist by the Swedish Council for Working Life and Social Research (2007-1754), King Gustaf V and Queen Victoria's Foundation 
of Freemasons, and by the National Heart, Lung, And Blood Institute of the National Institutes of Health under Award Number R01HL116381.

Competing interests None declared.

Ethics approval The study was approved by the Ethics Committee at Lund University and recommendations of the Declaration of Helsinki were complied with.

Provenance and peer review Not commissioned; externally peer reviewed.

Data sharing statement No additional data are available.

Open Access This is an Open Access article distributed in accordance with the Creative Commons Attribution Non Commercial (CC BY-NC 4.0) license, which permits others to distribute, remix, adapt, build upon this work noncommercially, and license their derivative works on different terms, provided the original work is properly cited and the use is non-commercial. See: http:// creativecommons.org/licenses/by-nc/4.0/

\section{REFERENCES}

1. Decramer M, Janssens W, Miravitlles M. Chronic obstructive pulmonary disease. Lancet 2012;379:1341-51.

2. Hersh CP, Hokanson JE, Lynch DA, et al. Family history is a risk factor for COPD. Chest 2011;140:343-50.

3. Hemminki K, Li X, Sundquist $\mathrm{K}$, et al. Familial risks for chronic obstructive pulmonary disease among siblings based on hospitalisations in Sweden. J Epidemiol Community Health 2008;62:398-401.

4. Jyrki-Tapani K, Sovijärvi A, Lundbäck B. Chronic obstructive pulmonary disease in Finland: prevalence and risk factors. COPD 2005;2:331-9.

5. Nihlén $U$, Nyberg $P$, Montnémery $P$, et al. Influence of family history and smoking habits on the incidence of self-reported physician's diagnosis of COPD. Respir Med 2004;98:263-70.

6. Berndt A, Leme AS, Shapiro SD. Emerging genetics of COPD. EMBO Mol Med 2012;4:1144-55.

7. Corvol $\mathrm{H}$, Hodges CA, Drumm ML, et al. Moving beyond genetics: is FAM13A a major biological contributor in lung physiology and chronic lung diseases? J Med Genet 2014;51:646-9.

8. Wain LV, Soler Artigas M, Tobin MD, et al. What can genetics tell us about the cause of fixed airflow obstruction? Clin Exp Allergy 2012;42:1176-82.

9. Meteran $\mathrm{H}$, Backer V, Kyvik KO, et al. Heredity of chronic bronchitis: a registry-based twin study. Respir Med 2014;108:1321-6.

10. Hallberg J, Dominicus A, Eriksson UK, et al. Interaction between smoking and genetic factors in the development of chronic bronchitis. Am J Respir Crit Care Med 2008;177:486-90.

11. Ingebrigtsen T, Thomsen SF, Vestbo J, et al. Genetic influences on chronic obstructive pulmonary disease-a twin study. Respir Med 2010;104:1890-5.

12. Burton PR, Tobin MD, Hopper JL. Key concepts in genetic epidemiology. Lancet 2005;366:941-51.

13. Manolio TA, Collins FS, Cox NJ, et al. Finding the missing heritability of complex diseases. Nature 2009;461:747-53.
14. Risch $\mathrm{N}$. The genetic epidemiology of cancer: interpreting family and twin studies and their implications for molecular genetic approaches. Cancer Epidemiol Biomarkers Prev 2001;10:733-41.

15. Rosen M, Hakulinen T. Use of disease registers. In: Ahrens W, Pigeot I, eds. Handbook of epidemiology. Berlin: Springer-Verlag 2005:231-52.

16. Ekbom A. The Swedish multi-generation register. Methods Mol Biol 2011;675:215-20.

17. Sundquist $\mathrm{K}$, Winkleby M, Li X, et al. Familial [corrected] transmission of coronary heart disease: a cohort study of 80,214 Swedish adoptees linked to their biological and adoptive parents. Am Heart J 2011;162:317-23.

18. Zöller B, Li X, Sundquist J, et al. Familial transmission of prostate, breast and colorectal cancer in adoptees is related to cancer in biological but not in adoptive parents: a nationwide family study. Eur J Cancer 2014;50:2319-27.

19. Zöller B, Li X, Sundquist J, et al. Familial transmission of venous thromboembolism: a cohort study of 80214 Swedish adoptees linked to their biological and adoptive parents. Circ Cardiovasc Genet 2014;7:296-303.

20. Ludvigsson JF, Andersson E, Ekbom A, et al. External review and validation of the Swedish national inpatient register. BMC Public Health 2011;11:45.

21. Zöller B. Nationwide family studies of cardiovascular diseasesclinical and genetic implications of family history. EMJ Cardiol 2013;1:102-13.

22. Ludvigsson JF, Otterblad-Olausson P, Pettersson BU, et al. The Swedish personal identity number: possibilities and pitfalls in healthcare and medical research. Eur J Epidemiol 2009;24:659-67.

23. Nordlöf B. Svenska Adoptioner i Stockholm 1918-1973 [Swedish Adoptions in Stockholm 1918-1973]. FoU-rapport 2001:8. Stockholm: Socialtjänstförvaltningen, Forsknings-och utvecklingsenheten, 2001.

24. Bohman M. Adopted children and their families-a follow-up study of adopted children, their background, environment and adjustment. Stockholm: Proprius; 1970.

25. von Borczyskowski A, Lindblad F, Vinnerljung B, et al. Familial factors and suicide: an adoption study in a Swedish National Cohort. Psychol Med 2011;41:749-58.

26. Inghammar M, Engström G, Löfdahl CG, et al. Validation of a COPD diagnosis from the Swedish Inpatient Registry. Scand J Public Health 2012;40:773-6.

27. Breslow NE, Day NE. Statistical methods in cancer research. Volume II-the design and analysis of cohort studies. IARC Sci PubI 1987;82:1-406.

28. Kaprio J, Hammar N, Koskenvuo M, et al. Cigarette smoking and alcohol use in Finland and Sweden: a cross-national twin study. Int $J$ Epidemiol 1982;11:378-86.

29. Global Initiative for Chronic Obstructive Lung Disease. Global strategy for the diagnosis, management, and prevention of chronic obstructive pulmonary disease.

30. Prieto-Centurion V, Rolle AJ, Au DH, et al. Multi-center study comparing case definitions used to identify patients with chronic obstructive pulmonary disease. Am J Respir Crit Care Med 2014;190:989-95.

31. Rothman KJ. No adjustments are needed for multiple comparisons. Epidemiology 1990;1:43-6. 